\title{
A Multi-Method Case Study of Textile Craft-Design Applications pÿ Usability and Effects on the Design Process
}

\section{Riikonen, Sini}

2018-10-01

Riikonen , S \& Seitamaa-Hakkarainen , P 2018 , ' A Multi-Method Case Study of Textile pÿCraft-Design Applications Usability and Effects on the Design Process ' , Art, Design and Communication in Higher Education, vol. 17 , no. 2 , pp. 217-236 . https://doi.org/10.1386/adch.17.2.217_1

http://hdl.handle.net/10138/324522

https://doi.org/10.1386/adch.17.2.217_1

cc_by

acceptedVersion

Downloaded from Helda, University of Helsinki institutional repository.

This is an electronic reprint of the original article.

This reprint may differ from the original in pagination and typographic detail.

Please cite the original version. 


\title{
A Multi-Method Case Study of Textile Craft -Design Applications - Usability and Effects on the Design Process
}

\begin{abstract}
This article presents a multi-method case study of five mobile device and desktop computer applications intended specifically for craft-design. The main aim of the study was to investigate the effects of application usage on the craft-design process and to analyse the usability of the applications from three perspectives: user experience, traditional usability and functionality. Eight master's level craft teacher students evaluated the applications and used those to conduct a design task on a Virtual Design Studio course at the University of Helsinki. To enable an authentic working environment and style for the participants and to gather research data remotely, a multi-method approach was designed that included data from questionnaires, written tasks and recordings of screen events. Analysis of the effects of application usage on the craft-design process revealed three factors that promote changes: the usability of an application, new possibilities and limitations compared to traditional design methods and the technical expertise of the designer - usability being the most significant factor behind the changes observed.
\end{abstract}

\section{Introduction}

The rapid development of information and communication technology (ICT) has brought it into nearly every area of everyday life, including craft. To retain the unique creative nature of craft in the Digital Era, deep understanding of the possible effects of digital design tool usage on the craft-design process is necessary. In this article, digital design tools refer to all ICT that can be used in the craft-design process, either as substitutes for traditional design tools or as completely new methods of designing.

Numerous studies have explored the nature of craft-design processes and other similar creative design processes (e.g. Goel \& Pirolli 1992; Authors 2001). Creative design processes, which are complex in nature, solve design problems consisting of a design task and design constraints outlining possible solutions (Buchanan 1995; Lawson 1997). Creative design processes are often described as iterative and spiral processes where different phases of the process intermingle and repeat until a desired design is achieved (e.g. Authors 2001; Lawson 1997; Pahl \& Beitz 1996). Similarly, usability is a widely studied area, although there is continued debate on the definition of the term (e.g. Jordan 2000; Nielsen 1993; McNamara \& Kirakowski 2006). However, little is known about how ICT usage affects the craft-design process and research on the field has been limited and scattered.

This article represents the findings of a qualitative case study focusing on five applications intended specifically for craft-design. The main research questions are:

- How does the usage of craft-design applications affect design constraints, design activities and the nature of the craft-design process?

- What effects does application usability have on the usage of applications and the design process? 
To create a natural working environment and style for the participants and to enable remote data gathering, a multi-method approach was designed for this research. In the following, we provide an overview of the theoretical aspects of the research and describe our research setting and methods. Finally, we report our results and discuss them in the light of education in the Digital Age and explore the implications of the research.

\section{ICT and craft-design}

\section{Design constraints}

To understand a complex design problem, a designer must recognize and set the design constraints that apply to the problem (Goel \& Pirolli 1992; Lawson 1997). ICT imposes new design constraints and changes or removes existing ones. Although ICT is commonly related to technical constraints, it may even govern the entire purpose of a design. Technical constraints are often quite inflexible in nature (Lawson 1997). Limitations in manufacturing techniques and materials or the different levels of craftsmanship skills of a maker cannot be overlooked. Technical constraints may also emerge from the limitations of digital design tools and the technical expertise required to use such tools. It has been suggested that in order to retain the creative nature and uniqueness of craft, learning to use digital tools is not enough. Truly creative craft-design requires learning to modify digital tools and even to make new ones (Verbruggen 2014; Taylor \& Townsend 2014; Masterton 2007). According to Masterton (2007), the inability to modify design tools may lead to a situation where the limitations of the tools guide the entire design process and lead designers to employ similar solutions and digital aesthetics in their designs instead of producing truly unique and creative work.

New digital technologies, such as Additive Manufacturing (AM) and digital textile printing, offer craftdesigners many new possibilities, for example, by rapid prototyping and the ability to design individual, tailor-made components. AM also creates new forms of craft, such as the production of unique hybrid artefacts combining traditional craft techniques and AM (e.g. Zoran \& Buechley 2013). It seems that many technical design constraints are already changing or disappearing entirely, and this process will only accelerate in the future. However, limited technical expertise is, and will remain, a significant constraint on progress towards the broader use of ICT among craft-designers and makers (Harris 2012).

\section{Finding inspiration}

Sources of inspiration help a designer move from the first vague mental image of an artefact to the final design through an iterative design process (e.g. Pahl \& Beitz 1996; Authors 2009). Sources of inspiration can be almost anything, such as memories, pictures, materials or tangible objects (Petre et al. 2006). ICT, and especially the Internet, provides a designer with an endless source of inspiration. It is, nevertheless, limited to immaterial things and removes the opportunity to gain inspiration through, for example, touch, taste or smell. 
Appiah and Cronjé (2012) have studied how the possibility to use ICT influences idea development and sketching in the design processes of graphic design students. They revealed that these students used the Internet to search for ideas - mostly for pictures that resembled their design task - rather than using other ways to find inspiration. Often the students made only minor modifications, if any, to the pictures until they arrived at their final design. According Appiah and Cronjé (2012), this significantly limited the students' creativity and resulted in the almost direct copying of designs. Furthermore, similar results have been found in interviews of designers working in digital textile craft-design (Authors 2009). In contrast, Lappola (2014), who studied the use of Pinterest as a communication channel for fashion design students and their clients, discovered that when students' main sources of inspiration were Pinterest boards without any pictures of clothing, they were not tempted to copy designs directly. This suggests that some of the problems may be prevented by avoiding overuse of certain types of inspiration sources.

\section{Sketching}

Sketching is considered to be a fundamental part of the design process, as it enables reinterpretations, brainstorming, and the gathering and further development of ideas (e.g. Goel 1995; Goldschmidt 1991; Lawson 1997; Authors 2004). Digital drawings are more precise than hand-drawn sketches, and that, according to Lawson (1997), may be destructive and restrictive, as the ambiguity of sketches creates the possibility of reinterpretations and the further development of ideas. The findings of Goel (1995) on differences between traditional and digital sketching support this view.

Stones and Cassidy (2010) repeated Goel's study with a modified task where participants had no restrictions on how they could use the design application; they could, for example, use freehand drawing and premade shapes. They discovered, in partial contradiction to Goel's (1995) findings, that the participants were able to make some reinterpretations from their digital sketches; however, they failed to lead to any further development of ideas or the creation of new designs. On the other hand, Jun-Chieh, Cheng-Chi and Hsin-Chia (2012) argue that modern digital drawing systems offer many advantages compared to traditional sketching. Built-in functions, such as 'undo', 'redo' and the possibility of using different kinds of lines and blurring create novel possibilities for designers to control the level of abstraction of their sketches.

Furthermore, working with actual materials by constructing models, test samples or prototypes is a common design method in craft-design (Binder et al. 2011; Ramduny-Ellis et al. 2010). Material representations in the various phases of the craft-design process provide diverse prompts to test design ideas. Purely digital design distances the designer from the artefact being designed by eliminating the opportunity for bodily experiences and the use of tacit knowledge to find new design solutions and reconceptualize the design problem (Philpott 2010; see also Sennett 2009). Masterton (2007) supports this view and observes that the speed of digital design tools does not necessarily leave sufficient time for creative thinking and deliberation, which may lead to the inability to recognize good ideas and further develop them.

Digital design also makes it difficult to tackle the imperfect nature of materials. While working with actual materials, the designer can take possible defects and the unexpected behaviours of materials into 
consideration. Virtual materials behave in the way they are digitally modelled to behave, without flaws or exceptions, in contrast to real materials, which are invariably non-uniform in nature. Noticing unforeseen issues in the materials can lead to new design solutions, but those opportunities are lost when working with digital design tools. As Sennett (2009) remarks, 'machines break down when they lose control, whereas people make discoveries'.

Recently, many relatively simple, more domain-specific, digital craft-design applications have become available, such as knitting pattern and weave structure applications. These digital applications are used in textile teacher education, but their applicability is usually restricted to the specifications of a particular production technique. To promote creativity and find the most suitable applications for students to use, more rigorous studies are needed that analyse the usability of applications and how students experience these digital tools.

\section{Usability}

In this study, usability is considered to be a combination of three separate but partially interlinked factors: functionality, traditional usability and user experience. Such an approach has been suggested in previous studies by, among others, Jordan (2000) and McNamara and Kirakowski (2006) Functionality is considered a technical issue concerning whether an application has the required qualities and functionality to perform the tasks for which it is intended (see Nielsen 1993; Jordan 2000; McNamara \& Kirakowski 2006). Traditional usability is evaluated with Nielsen's (1993) model of usability and usability standards (ISO 1998; ISO/IEC 2011). The evaluation of user experience is based on the ISO 9241-210 standard (ISO 2010).

Nielsen's (1993) model defines usability though five attributes: learnability, efficiency, memorability, errors and satisfaction. These attributes are individually measureable, but as Nielsen (1993) observed, changing one attribute may significantly influence the other attributes and improving a system in one area may not lead to better overall usability. ISO 9241-11 (ISO 1998), on the other hand, defines usability through effectiveness, efficiency and satisfaction: '[usability refers to the] extent to which a product can be used by specified users to achieve specified goals with effectiveness, efficiency and satisfaction in a specified context of use'.

The more recent standard, ISO/IEC 25010 (ISO/IEC 2011), defining usability as quality in use, gives usability a similar - albeit wider and more user-centred - definition. The user-centred approach of ISO/IEC 25010 (ISO/IEC 2011) reflects the trend in usability research towards focusing more on user experience. Although both Nielsen's (1993) model of usability and the ISO 9241-11 (ISO 1998) standard include concepts like 'subjectively pleasing' and 'satisfaction', those models are often considered to overemphasize ease of use and the technical qualities of a product (e.g. Seffah et al. 2006).

The ISO 9241-210 standard (ISO 2010) defines user experience as: 
'[a] person's perceptions and responses resulting from the use and/or anticipated use of a product, system or service [...] User experience includes all the users' emotions, beliefs, preferences, perceptions, physical and psychological responses, behaviours and accomplishments that occur before, during and after use.'

Although user experience seems to be closely related to traditional usability (e.g. Nielsen 1993; ISO 1998), the two have some elementary differences. Traditional usability is task and performance-oriented, it relies on the tradition of objective testing and measuring and it focuses on finding and fixing problems. User experience, in contrast, aims also to take non-task-related factors, such as beauty and selfexpression, into consideration. It highlights users' subjective views on a product and emphasizes the positive effects of its use and possession (Hassenzahl et al. 2006).

\section{Method}

\section{Research setting}

For this research, five applications intended for craft-design were chosen from a pre-gathered list of 64 applications. In order to ensure their suitability for this research and for craft teacher students to use in their studies, three preliminary criteria were determined for the applications: 1) that they cost less than 50 euros, 2) that they were actively maintained and 3) that they were available for the Apple iOS or Microsoft Windows operating system. Further elimination of unsuitable applications took place on the basis of the researcher's own judgement and ICT expertise. The applications chosen for this study were CStitch for embroidery, iWeaveIt for weaving, Knitting iCharts for knitting, StitchSketch for embroidery, knitting, crochet and beadwork, and Weaving Sim for weaving. Three application pairs were formed from these applications: 1) Knitting: Knitting iCharts and StitchSketch, 2) Embroidery: StitchSketch and CStitch and 3) Weaving: iWeaveIt and Weaving Sim. Every participant tested one application pair. To ensure that the craft technique itself did not constrain the design process to excess and thus limit the usability evaluation, participants were given a possibility to choose, which application pair they wanted to test.

The research data were gathered on a Virtual Design Studio course held at the University of Helsinki in spring 2015. The course was an optional advanced craft-science studies course for master's degree students. Eight female students, identified by the letters A to H, participated in the research. They had very little or no previous experience of craft-design applications. The Virtual Design Studio course utilized the Moodle online learning platform, and the course tasks were completed as remote work over the Internet. The course had three 90-minute face-to-face meetings that were used to give the students the necessary instructions for the course tasks, support completion of the tasks and allow for discussion on the students' experiences of the applications. 


\section{Multi-method approach to data gathering}

The need to develop a remote data collection method was twofold: to create an authentic working environment and style for the participants and to enable data collection on the Virtual Design Studio course. Therefore, a method was required that was unmoderated and did not interfere with the design process. The aim was to collect both data that highlighted the participants' subjective experiences, attitudes and opinions (attitudinal data) and also observable data that was not based on those subjective factors (behavioural data). The challenge in this study was to find a set of methods that met the above criteria and was applicable to both usability evaluations and design research.

The multi-method approach designed for this study synthesized three individual data collection methods: 1) video recording of screen events, 2) qualitative questionnaires and 3) writing tasks. Screen event recording produced objective behavioural data for analysing both usability and design processes. The questionnaires and writing tasks were intended to provide rich descriptive and attitudinal data on both areas of interest.

The students were given a design task that functioned as both the task used for gathering data and the assignment students needed to complete in order to pass the course:

'Design "an interior thing", i.e. an interior textile or a decorative object with a textile surface. Design the whole product or the surface of the product with the application you have been given for testing. [...] Design one individual version of the same product with each of the applications you are testing.'

While working with their designs, the students were instructed to pay attention to the characteristics of their individual design processes and to the usability of the applications.

The research method contained two qualitative questionnaires for each application: the first (Q1) at the beginning of the course for collecting data on first impressions of the applications, the second (Q2) after the design task to gain insight into the usability of the applications. Both questionnaires primarily contained open-ended questions, but the participants were also asked to grade the application on a scale of 4 to 10 and to evaluate it on a so-called System Usability Scale (SUS) (Brooke 1996). The SUS is not originally intended for qualitative usability evaluation; therefore, placing it in this questionnaire was a very unorthodox way of using it. However, there were several reasons for doing so: it is designed for measuring users' personal views on the usability of a product (Brooke 2013); it concentrates on the usability of a product as a whole, instead of focusing on the usability of specific product features (Tullis $\&$ Stetson 2004); the definition of usability in the SUS is based on the ISO 9241-11 standard (Brooke 2013) and the SUS is quick to answer and a useful tool for helping participants pay attention to the different aspects of usability and thus provide more in-depth answers to the open-ended questions.

VLC media player was chosen for screen recording on desktop devices, while for the mobile applications the participants were provided with iPads with the applications and recording software, Shou, 
preinstalled. Shou was chosen because no cracking the devices to remove manufacturers restrictions on the operating system was required and because it enabled fully stand-alone screen recording without cables or application restrictions.

The multi-method approach also contained two writing tasks. In the first writing task, the participants were asked to describe their design process and how use of the applications affected it. The second task asked participants to write about their user experiences and brainstorm how the applications and ICT in general could be used creatively in craft.

The timing of the individual methods was of the essence in this multi-method approach. It guided the participants through the design process and data gathering tasks. The progression and timing of this multi-method approach and the fields of interest of the individual methods are illustrated in figure 1.

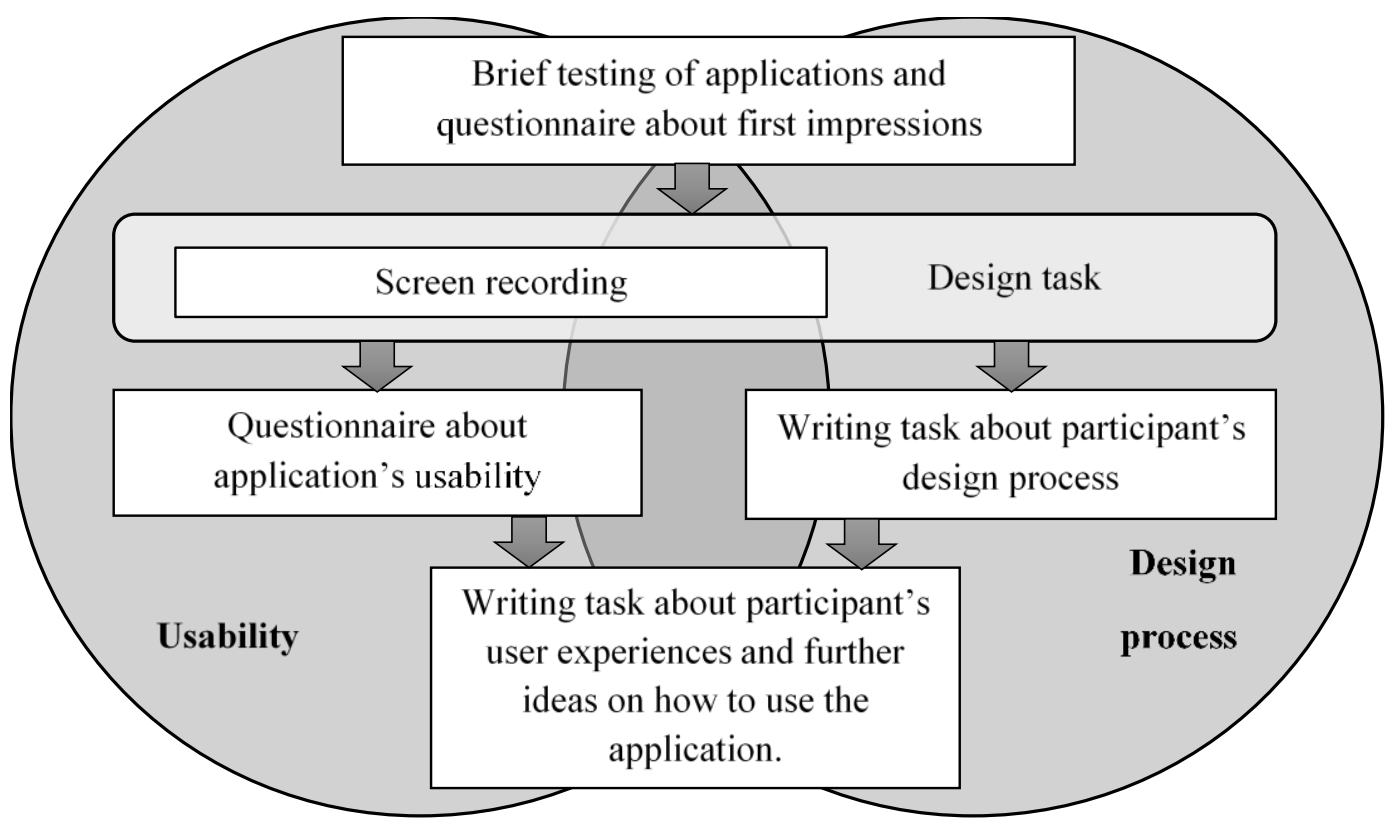

Figure 1: Progression and timing of the multi-method approach and fields of interest of individual methods 


\section{Data analysis methods}

The research data consisted of two sets of qualitative questionnaire answers, screen event recordings and two sets of writing. The open-ended questions in the questionnaires produced answers that ranged from 1 to 173 words and averaged from 29 to 71 words. A total of almost 11 hours of video data was provided by the participants (Table 1). Despite some missing recordings, video data were collected for every application. When analysing the usability of applications that received only one recording, the video data were treated as a supplementary source of information.

Table 1: Distribution of the video data between applications and participants

\begin{tabular}{|l|c|c|c|c|c|c|c|c|c|}
\cline { 2 - 10 } & \multicolumn{7}{|c|}{ Duration of video data (min:sec) } & $\begin{array}{c}\text { Total } \\
\text { min:sec }\end{array}$ \\
\cline { 2 - 11 } & A & B & C & D & E & F & G & H & \\
\hline CStitch & & & & & & $13: 37$ & N/A & N/A & $\mathbf{1 3 : 3 7}$ \\
\hline iWeaveIt & & & $81: 17$ & & $50: 46$ & & & & $\mathbf{1 3 2 : 0 3}$ \\
\hline Knitting iCharts & $63: 09$ & N/A & & $35: 10$ & & & & & $\mathbf{9 8 : 1 9}$ \\
\hline StitchSketch & $8: 26$ & N/A & & $16: 20$ & & $99: 23$ & $155: 52$ & $67: 34$ & $\mathbf{3 4 7 : 3 5}$ \\
\hline Weaving Sim & & & $53: 09$ & & N/A & & & & $\mathbf{5 3 : 0 9}$ \\
\hline Total mm:ss & $\mathbf{7 1 : 3 5}$ & N/A & $\mathbf{1 3 4 : 2 6}$ & $\mathbf{5 1 : 3 0}$ & $\mathbf{5 0 : 4 6}$ & $\mathbf{1 1 3 : 0 0}$ & $\mathbf{1 5 5 : 5 2}$ & $\mathbf{6 7 : 3 4}$ & $\mathbf{6 4 4 : 4 3}$ \\
\hline
\end{tabular}

All datatypes, excluding SUS scorings and grades given to the applications, were analysed with Atlas.ti software, version 7.5.10, following the procedures of qualitative content analysis (e.g. Mayring 2000). The data were divided into categories to structure and simplify the analysis: one data category related to design processes, and separate categories were included for individual applications, with an additional category for background information. The data categories were analysed separately and later compared with each other and analysed together.

The coding framework, presented in Table 2, was formed both inductively and deductively (e.g. Mayring 2000; Hsieh \& Shannon 2005). Three main categories were defined deductively: design context, design process and usability. To enable cross-case synthesis analysis (see Yin 2003), certain data types were not restricted to specific coding categories. An additional main category, comparison, emerged from the data during the first round of analysis. 
Table 2: Coding framework for qualitative content analysis

\begin{tabular}{|c|c|c|c|}
\hline $\begin{array}{l}\text { Main } \\
\text { category }\end{array}$ & $\begin{array}{l}\text { Predefined } \\
\text { subcategories (codes) }\end{array}$ & Subcategories (codes) added during analysis & $\begin{array}{l}\text { Additional descriptive codes } \\
\text { added during analysis }\end{array}$ \\
\hline Comparison & & comparison & $\begin{array}{l}\text { pen and paper, to other } \\
\text { applications }\end{array}$ \\
\hline \multirow[t]{3}{*}{$\begin{array}{l}\text { Design } \\
\text { context }\end{array}$} & $\begin{array}{l}\text { abnormal design } \\
\text { context, normal design } \\
\text { context }\end{array}$ & & \\
\hline & location & & $\begin{array}{l}\text { bus, train etc., home, school, } \\
\text { several }\end{array}$ \\
\hline & & $\operatorname{mood}$ & \\
\hline $\begin{array}{l}\text { Design } \\
\text { process }\end{array}$ & & $\begin{array}{l}\text { aesthetics, colour design, design constraints, } \\
\text { experimenting, first mental image, further } \\
\text { development of ideas, inspiration, material } \\
\text { consciousness, mental level designing, } \\
\text { sketching, structural design }\end{array}$ & $\begin{array}{l}\text { new blank design, start from } \\
\text { previous sketch, sketch } \\
1 \text {...sketch } 9, \text { less experimental, } \\
\text { more experimental, no action }\end{array}$ \\
\hline \multirow[t]{4}{*}{ Usability } & $\begin{array}{l}\text { context coverage, } \\
\text { efficiency, errors, } \\
\text { learnability, } \\
\text { memorability }\end{array}$ & & $\begin{array}{l}\text { awkward, clear, complex, easy, } \\
\text { slow }\end{array}$ \\
\hline & user experience & & $\begin{array}{l}\text { annoying, boring, confusing, } \\
\text { encouraging, frustrating, happy, } \\
\text { interesting, irresolute, } \\
\text { satisfying, unsure }\end{array}$ \\
\hline & functionality & & $\begin{array}{l}\text { missing feature, simple, } \\
\text { suggestion, too simple }\end{array}$ \\
\hline & $\begin{array}{l}\text { negative usability, } \\
\text { positive usability }\end{array}$ & & $\begin{array}{l}\text { browsing through menus, } \\
\text { usability problem }\end{array}$ \\
\hline
\end{tabular}

Segmentation of the data was performed using thematic criteria. The coding procedure was further defined by placing the data in a specific order for analysis. In the first round of analysis, all video data were analysed before any written or questionnaire data were even read. This was designed to ensure that the participants' opinions or remarks on possible errors or usability problems did not affect the analysis. Next, all written data were analysed. During the second round of analysis, the participants' observations were compared with the video data to find further connections. The cycles of analysis were repeated after two rounds for those parts of the data where the coding between the first two rounds did not match, until no changes occurred.

The SUS answers were analysed using scoring provided by Brooke (1996). Although SUS scores are numeric values, no statistical analysis of the scores was conducted. The scores were converted into adjectives, based on the scale developed by Bangor et al. (2009) (figure 2). 


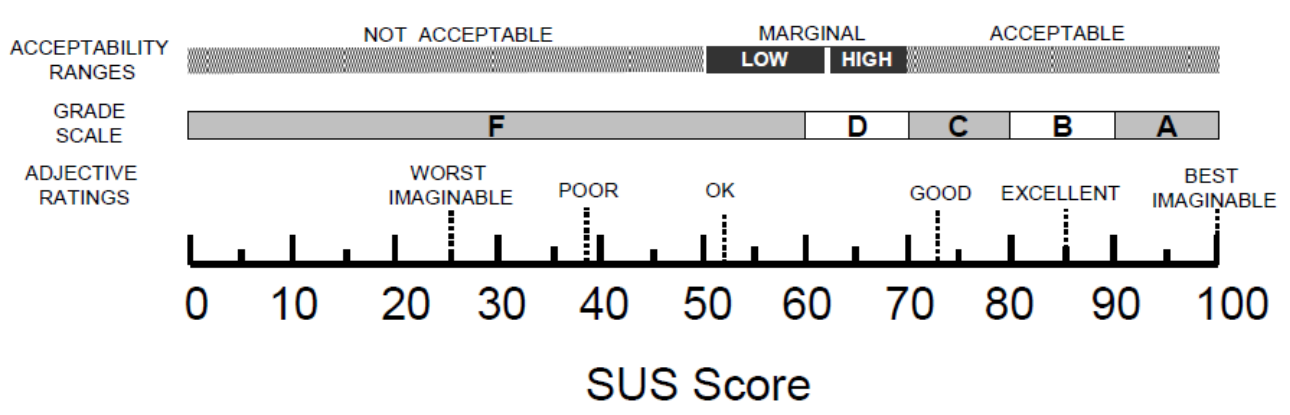

Figure 2: Adjective ratings in relation to the average SUS score (Bangor et al. 2009).

\section{Results}

\section{Usability of the applications}

The data analysis revealed significant differences in the applications' usability. CStitch was found to be very poor in all three dimension of usability. The participants expressed strong negative emotions, such as anger, concerning the application, and the video data revealed several usability problems. On the other hand, iWeaveIt was found to be a highly usable application, although some minor problems were reported regarding its functionality. During the video analysis, no usability issues were observed, and the design processes seemed effortless with iWeaveIt. Both participants who evaluated iWeaveIt reported having had a positive user experience with it.

The analysis revealed that the functionality, context coverage and efficiency of Knitting iCharts left room for improvement, whereas its learnability and memorability were considered excellent. All the participants were willing to recommend it, at least to some degree, to other craft teacher students, but some remarked that it was too simple and therefore better suited to craft hobbyists and primary and lowersecondary school pupils. User experiences of Knitting iCharts were twofold: the participants felt good about the application's ease of use but expressed feelings of frustration and aggravation towards its limited functionality. Participant D was particularly inspired by the application and expressed strong positive emotions towards it. Therefore, the overall usability of the application was evaluated as excellent for some users and for simple designs but not optimally suited to everyone and to every design task.

StitchSketch was evaluated as excellent for most users, but too complex for some. All the participants praised its features and versatility. Those attributes, however, seemed to impair its learnability by lengthening the learning processes. No actual errors were reported in StitchSketch, and those who learned to use it sufficiently well during the test period found it efficient. User experiences of StitchSketch were manifold, but they mostly changed from negative to positive during the design process. Aggravation and frustration at the beginning turned into satisfaction and joy at the end.

Q2, F: 'Negative [emotions] at first, later nothing but positive.' 
All the participants felt that StitchSketch's versatility meant it offered sufficiently advanced opportunities for creative craft-design and hence was suited to higher education.

The traditional usability of Weaving Sim was rated as either good or moderate, depending on the purpose of use. During the video analysis, no actual usability problems were detected, but the design work appeared to be slow and inefficient, which also emerged from the participants' writing. Some features, however, such as the ability to draw treadling and threading sequences by dragging the cursor were considered to increase Weaving Sim's efficiency. Both the participants who tested the application, C and E, agreed that Weaving Sim was very easy to learn to use. However, the simplicity of the application divided opinions: participant $\mathrm{C}$ liked it, but participant $\mathrm{E}$ felt that the application was overly simple and lacked key functionalities. Both participants reported that the application lacked versatility and was only suitable for simple design tasks.

Q1, E: 'On the other hand easiness is a plus but still the application is somehow barren and clumsy. [...] The joy caused by fast learning soon turned to aggravation when I started to feel that the application only had a very limited selection of features.'

The SUS scores and common Finnish school grades (4-10) given to the applications mirrored the written evaluations and video data (see Table 3). The SUS scores corresponded to the applications' traditional usability, whereas the school grades also reflected user experiences. However, the functionality of the applications failed to emerge from the ratings as clearly as the other two factors. Applications lacking in functionality received higher scores than the analysis of written and video data gave cause to expect. The divided opinions on Knitting iCharts and StitchSketch were nevertheless visible in both scores.

Table 3: Minimum and maximum school grades and the SUS scores and corresponding adjective ratings given to the applications

\begin{tabular}{|l|c|c|c|c|c|c|}
\cline { 2 - 7 } \multicolumn{1}{c|}{} & \multicolumn{3}{c|}{ First impressions (q1) } & \multicolumn{3}{c|}{ Usability (q2) } \\
\hline Application & $\begin{array}{c}\text { min-max } \\
\text { SUS score }\end{array}$ & $\begin{array}{c}\text { SUS Adjective } \\
\text { rating }\end{array}$ & $\begin{array}{c}\text { min-max school } \\
\text { grade (4-10) }\end{array}$ & $\begin{array}{c}\text { min-max } \\
\text { SUS score }\end{array}$ & $\begin{array}{c}\text { SUS Adjective } \\
\text { rating }\end{array}$ & $\begin{array}{c}\text { min-max school } \\
\text { grade (4-10) }\end{array}$ \\
\hline CStitch & 7.5 to 15 & worst imaginable & 4.75 to 6 & $15-30$ & worst imaginable & 5 to 6 \\
\hline iWeaveIt & 67.5 to 72.5 & OK & 8 & $75-87.5$ & good - excellent & 8 to 8.75 \\
\hline $\begin{array}{l}\text { Knitting } \\
\text { iCharts }\end{array}$ & 75 to 92.5 & good - excellent & 8 to 9 & 67.5 to 97.5 & OK - excellent & 6 to 9.5 \\
\hline StitchSketch & 22.5 to 75 & $\begin{array}{c}\text { worst imaginable } \\
\text { - good }\end{array}$ & 6 to 9.25 & 20 to 85 & $\begin{array}{c}\text { worst imaginable - } \\
\text { excellent }\end{array}$ & 7 to 9 \\
\hline Weaving Sim & 82.5 to 95 & good - excellent & 6 to 9 & 75 to 77.5 & good & 6 to 8 \\
\hline
\end{tabular}

\section{The effect of application usage on craft-design processes}

Based on the participants' writing, their design processes began with a vague mental image of a product. Most of the products the participants chose to design featured a flat and relatively small rectangular 
surface to which the design, made with the applications, was intended for. In addition, most of the products were common decorative items, such as pillows, which were relatively simple in structure.

Ultimately, all the participants designed extremely geometrical and symmetrical shapes that followed the grid logic of pixel art (see figures 3 and 4). Participant $G$ was the only one who even experimented with free-hand drawing and shapes that were not strictly geometrical (figure 5). Nevertheless, she also chose a geometrical pattern for her final design. Interestingly, participant $\mathrm{G}$ was the only participant to report that her whole design process had been guided by the applications and the possibilities they offered. The other participants described factors such as material and craft technique related issues as their design constraints.

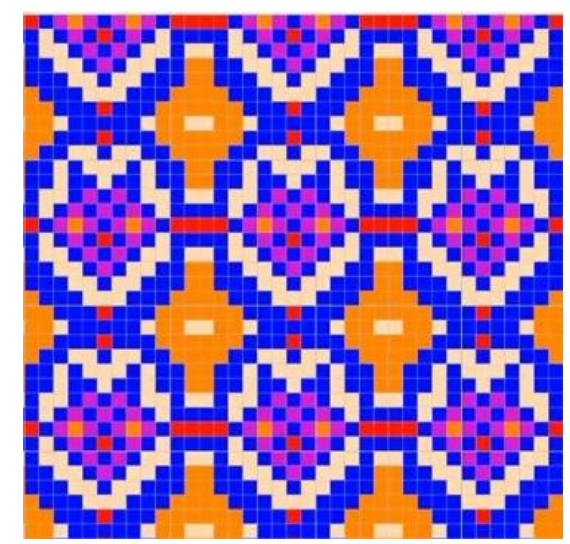

Figure 3: H's final design with StitchSketch

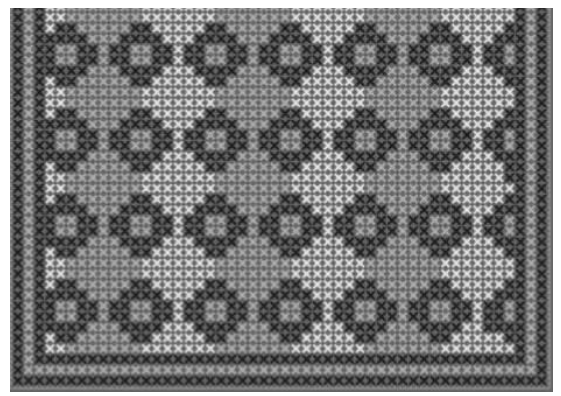

Figure 4: C's final design with StitchSketch

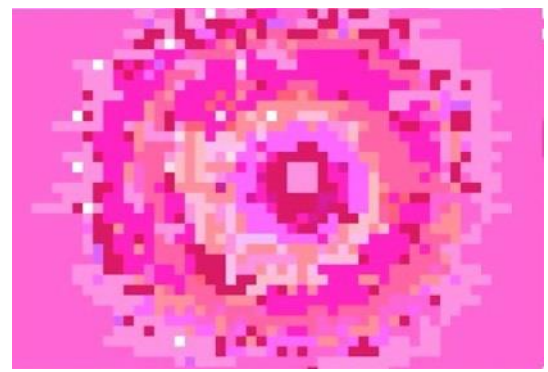

Figure 5: A non-geometrical design with StitchSketch by G

During the usability analysis, it became evident that usability was a significant design constraint in itself and had a significant effect on the nature of the craft-design process. The videos showed that with more usable applications the participants produced more sketches, experimented and further developed their ideas more, designed more advanced patterns from scratch and more extensively experimented with the application's functionalities than was the case with applications with poorer usability. With the applications with better usability, the design process became more iterative and cyclical in nature. In their writing the participants also reported enjoying designing with those applications. In contrast, the less usable applications led the participants to feel unmotivated, they tried to design as quickly as possible and their design processes were reduced to linear processes with no further development of ideas and small number of sketches that were often based on a design made with another application.

Q2, Cstitch, H: 'The application made me constantly feel frustrated and aggravated. I felt clumsy and almost lost faith every now and then. [...] I didn't get any feelings of success. I somehow rushed using the application because I was afraid that I would mess up and even entirely erase a design by accident. I didn't feel like slowing down, experimenting and playing with the design.' 
The functionality of the applications was described as a constraint on several occasions. For example, participant $\mathrm{G}$ was unable to make the design she wanted because the application failed to offer the possibility of mixing colours. Moreover, participant $\mathrm{D}$ wrote:

'My first idea was to make a star pattern. But no matter how hard I tried, I couldn't produce a nice-looking star pattern with the application. [...] Next an idea crossed my mind about a heartshaped pattern and I started to like it. With the application, I was able to design nicely shaped hearts that I was satisfied with.'

Functionality also seemed to be the usability factor with the greatest effect on design activities and the nature of the design process. Participant C's design processes are a good example of the effects of application functionality. She made seven individual sketches showing further development of ideas with iWeaveIt, which based on the usability analysis had good functionality (figures 6-12). In addition, numerous instances of experimentation with application features and design possibilities were observed in the videos. In contrast, her design process with Weaving Sim was very short and linear: she made just two sketches based on the design made with iWeavelt, and they contained only slight modifications to the initial design (figures 13 and 14). Although participant C liked Weaving Sim in terms of the other usability factors, its functionality shortcomings affected her design process significantly.

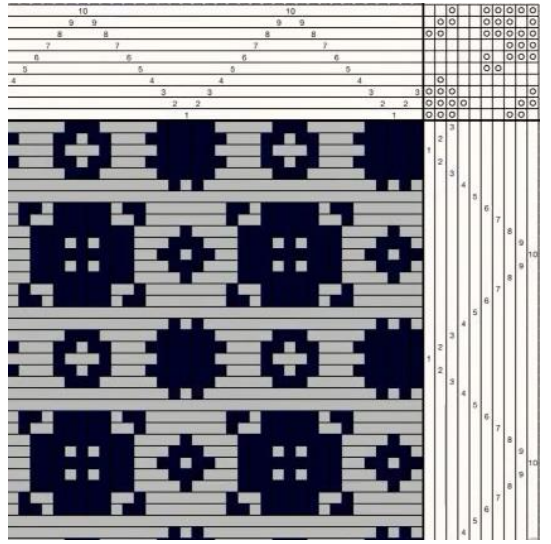

Figure 6: C's iWeaveIt sketch 1

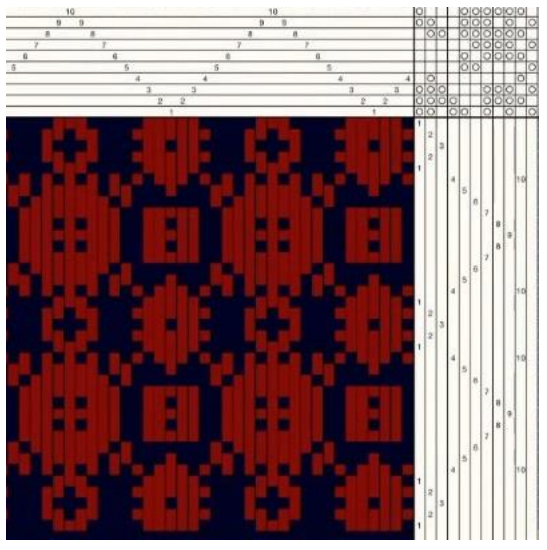

Figure 9: C's iWeaveIt sketch 4

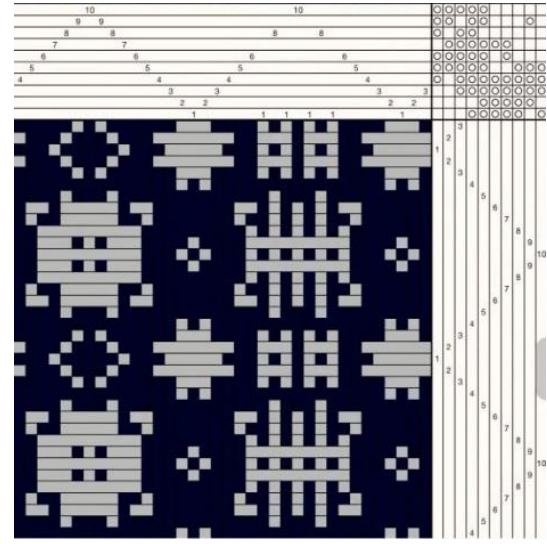

Figure 7: C's iWeaveIt sketch 2
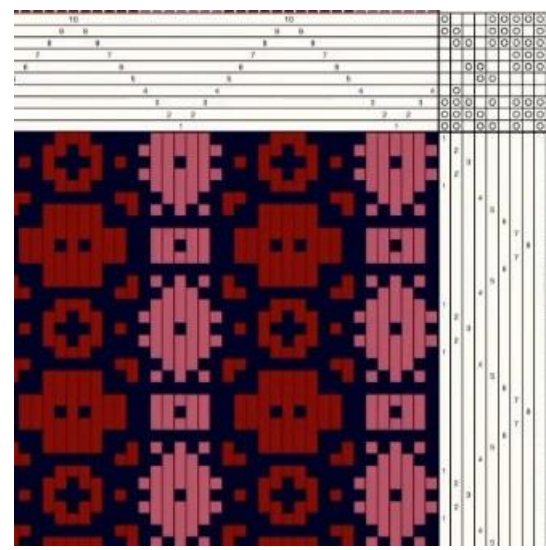

Figure 10: C's iWeaveIt sketch 5

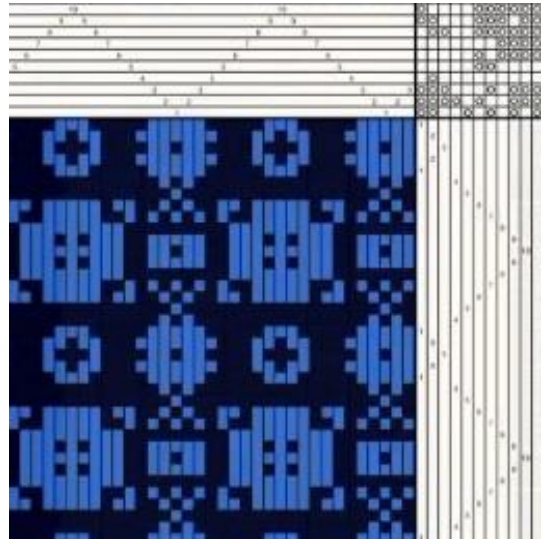

Figure 8: C's iWeaveIt sketch 3

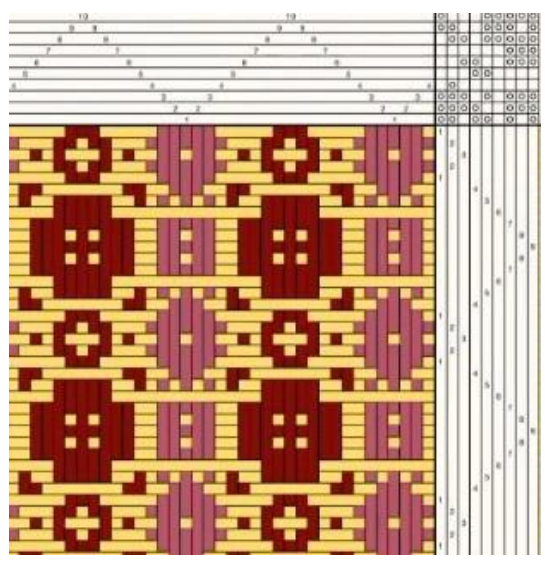

Figure 11: C's iWeaveIt sketch 6 


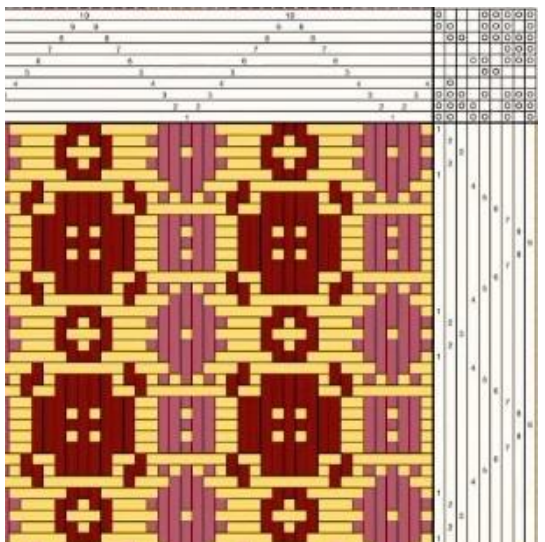

Figure 12: C's iWeaveIt sketch 7

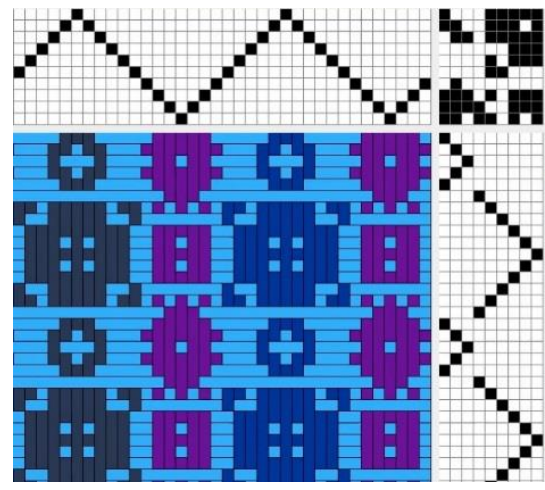

Figure 13: C's Weaving Sim sketch 1

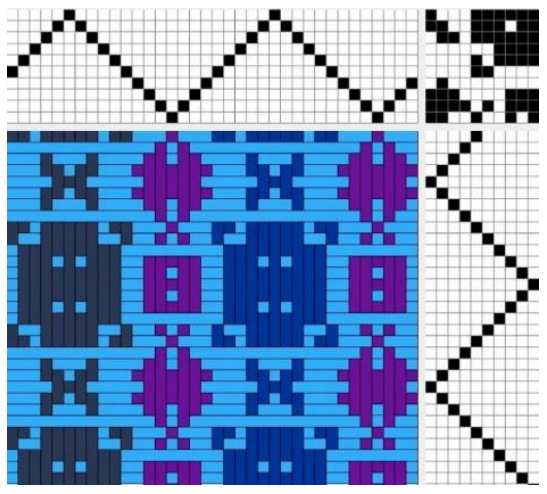

Figure 14: C's Weaving Sim sketch 2

Although in most cases the participants' sketches were not ambiguous (as mentioned earlier sketch ambiguity is an important element of the creative process), they were still able to make reinterpretations and further develop their ideas. The new possibilities offered by the applications, such as easy colour changes and cut, copy and erase features, were also mentioned and emphasized on many occasions as beneficial to the design work.

Although the participants were required to design one version of their product's surface with each of the applications, they were not forbidden from using other methods of design. This freedom was used by many of the participants. Participant A and D, for example, experimented with real materials by making samples of their sketches (figures 15-18).

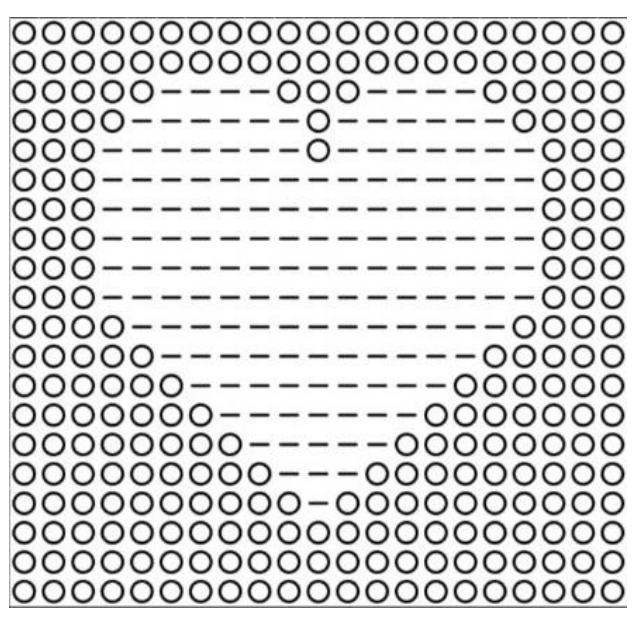

Figure 15: D’s sketch

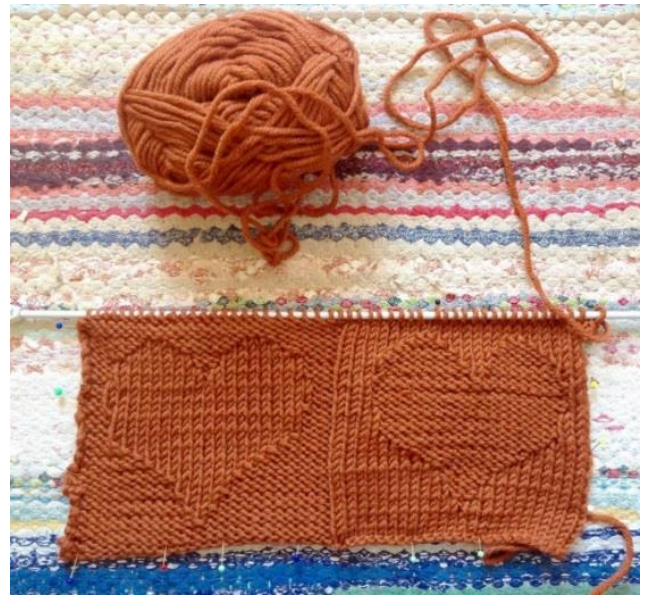

Figure 16: D’s material experiment 


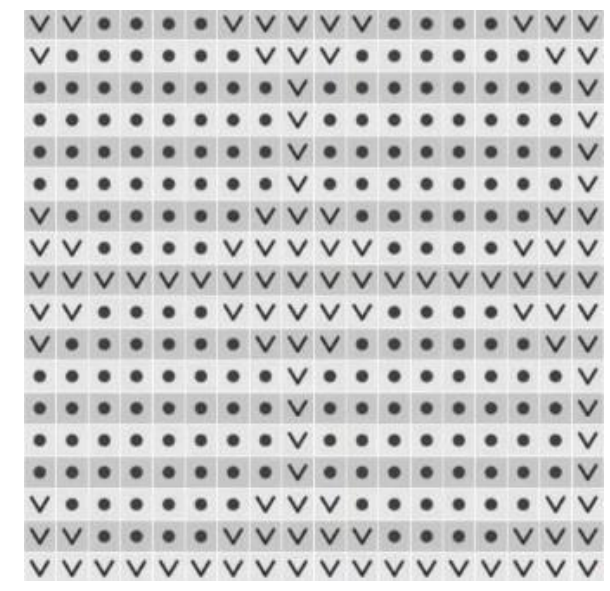

Figure 17: A's sketch

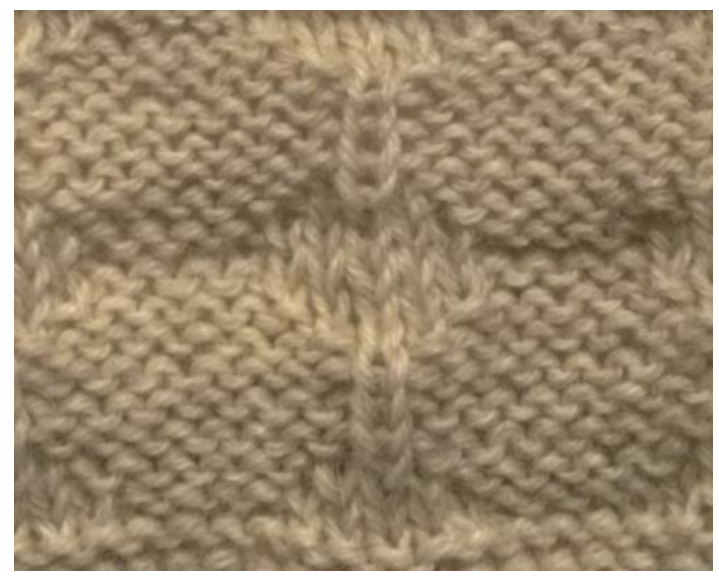

Figure 18: A's material experiment

Several participants wrote about the materials they were planning to use and how they took the characteristics of the materials into consideration. Furthermore, remarks about haptic experiences were made in the participants' writing.

D: 'The quality of the yarn was selected next; it really called for merino wool. It's warm, fluffy and the superwash treatment makes it machine washable. I chose a relatively thick thread so that it would be warm and faster to knit.'

Several participants shared Harris's (2012) concern that lack of technical expertise would slow progress towards the broader use of digital design tools among craft-designers. The participants emphasized the importance of integrating ICT into craft-science studies to overcome this problem and to give future craft teachers the expertise they need to pass on to their students.

In this research, no direct copying of sources of inspiration was detected. The sources of inspiration described by the participants varied. Some participants drew their inspiration from the environment, some sought inspiration from discussion with others or by browsing the internet or books and some were inspired by experimenting with the applications. Based on the written data, the applications introduced a potential new source of inspiration but did not promote the direct copying of ideas. Nevertheless, it must be noted that no observable behavioural data on sources of inspiration were collected.

\section{Conclusions}

The main objective of this study was to analyse and describe how the usage of craft-design applications affected design constraints, design activities and the nature of the craft-design process. Evaluating the usability of the applications was considered an important element of the research.

Based on overall usability, the most usable applications evaluated in this study were iWeaveIt and StitchSketch. For simple design tasks and users seeking applications that are easy to learn, Knitting 
iCharts and Weaving Sim may also be suitable. Those applications, however, lacked functionality to such extent that they were unsuited to design tasks requiring more advanced features or functionalities.

The analysis of application usage in craft-design processes revealed three factors that promote changes:

- the usability of applications

- new possibilities and limitations compared to traditional design methods

- $\quad$ the technical expertise of the designer

Application usability was the most significant factor behind the changes observed in the craft-design processes, and it was also perceived to be a significant design constraint in itself. For those applications with better usability, the craft-design process became more iterative and cyclical in nature. With the less usable applications, the design process was reduced to a linear process with no further development of ideas.

Functionality seems to be the usability factor that has the greatest effect on design constraints, design activities and the nature of the design process. The functionality of an application and the interpretations made about its the functionality and logic imposed strong technical design constraints that framed entire design processes (see Lawson 1997). In particular, the grid-based, geometrical logic of the applications seemed to guide the designs strongly towards a similar logic, which supports Masterton's (2007) findings in a previous study.

The reinterpretations and further development of ideas observed in this research while the participants used the applications with the best usability contradict the findings of Goel (1995) and Stones and Cassidy (2010). However, neither of these previous studies analysed the usability of digital design tools. It is possible that the digital design tools used in those studies lacked sufficient usability and therefore reinterpretations and the further development of ideas failed to occur. Regarding Goel's (1995) research, this is a highly plausible explanation, as digital design tools have rapidly developed in the past 20 years. Moreover, the contradiction with the findings of Stones and Cassidy (2010) may also be due to the place and time limitations they placed on their participants. In their research the participants had only 25 minutes for one design task in a pre-defined environment, whereas this study aimed for a natural design environment without time limitations. In addition, Goel (1995) and Stones and Cassidy (2010) investigated digital free-hand drawing. However, digital design tools are likely to be more suitable for craft-design, as many textile craft techniques follow the same geometrical logic as digital design tools. Furthermore, the sketches made with digital design tools for craft-design may be easier to picture, especially in the case of large surfaces, and therefore digital design tools actually promote reinterpretation and the further development of ideas in craft-design.

The participants overcame the lack of bodily experience and the inability to design with real materials in purely digital design, which, according to Philpott (2010), distance the designer from the artefact and eliminate the possibility of using tacit knowledge. They accomplished this by using the applications alongside other forms of design, such as material experiments. Several participants wrote about the 
materials they were planning to use and how they took the characteristics of the materials into consideration in their design. Furthermore, remarks about haptic experiences were made in the participants' writing. This indicates that although the digital design tools did not directly produce tactile experiences or facilitate designing with real materials, the participants were able to use their tacit knowledge and incorporate additional design techniques alongside the digital design.

In addition to the other factors, the technical expertise of the participants constrained the design processes. In this study all the participants were inexperienced with craft-design applications, and some also lacked experience with tablet devices. They were in the early stages of learning how to use such applications and devices, and they were unable to modify the applications to better support their design processes. In their writings, the participants reported feeling that this lack of technical expertise limited their design processes and the creative usage of applications. This supports the findings of previous studies (e.g. Verbruggen 2014; Taylor \& Townsend 2014; Masterton 2007).

\section{Limitations of the study}

From a methodological perspective, the remote multi-method approach developed for this research fulfilled the main goals set for it. It gave the participants the possibility to work in their natural environment without time or place limitations and still produced rich attitudinal and behavioural data. None of the participants reported being disturbed by the video recording of the screen events. It also proved to be highly efficient in terms of resources, such as the time and effort required from the researcher and the participants for data collection.

The most significant factor limiting the reliability of the results in this study is the low number of participants. However, the multidimensional data compensated for this by offering the possibility of triangulation to validate the results. In most cases, the inter-participant data were also consistent, which further validates the findings (e.g. Yin 2003).

Furthermore, the results could have been further validated by conducting the same design task using traditional, analogue, design methods, either with the existing participants or another set of students, and then make a comparison between the design processes. However, using another set of students was not possible and we could not divide the existing participants into two groups due to the low number of participants and as and analogue design task alone would not have corresponded to the scope of the Virtual Design Studio course. We did not add analogue design task to the course assignment either because we wanted the participants to use the limited extent of the course to extensive testing and working with the applications. Adding the analogue part to the design task would have forced us to cut down other parts of the course assignment that, in our opinion, would have been detrimental to this research.

Finally, the results of this study are based on interpretations made by the researcher. To avoid fallacious results, the analysis was based on qualitative content analysis and the data were analysed in a 
predetermined order. This systematic approach and multiple rounds of analysis, combined with the triangulation of results, increase the reliability of the results significantly.

\section{Discussion}

This study helped develop understanding, both practical and theoretical, of the effects of application usage on the craft-design process. To confirm the study's findings and to gain even more insight into the phenomenon, further research is essential. All three factors that seemingly affect the craft-design process are interesting subjects for future research. In addition, there may be additional factors that will emerge in future research or as a result of technological development.

The knowledge gained in this research is important because ICT is quickly making its way into craft, especially the teaching of craft. If the effects of application usage are unknown and digital design tools are nevertheless used in teaching, the danger is that the creative, iterative and cyclical nature of craftdesign may be lost. A more profound understanding of this phenomenon and the identification of suitable digital design tools for craft-design may nevertheless transform this risk into an opportunity.

Policy-makers and educators at all levels of education where craft is taught should recognize the unique nature of craft. Although ICT is an important area of education today, it should nonetheless be seen as a tool and a catalyst for new opportunities and not as an end in itself. When claims are made about how ICT should be used in craft education, those making the claims should understand the potential effects of ICT on craft and its unique nature and how craft can benefit from ICT. To promote knowledge, discussion and policy-making that is based on facts rather than beliefs, this research and other studies made in this field are essential.

\section{References}

Appiah, E., \& Cronjé, J. C. (2012). Thumbnail sketches on idea development: The drawing board vs computer generation. Art, Design \& Communication in Higher Education, 11(1), 49-61.

Bangor, A., Kortum, P., \& Miller, J. (2009). Determining What Individual SUS Scores Mean: Adding an Adjective Rating Scale. Journal of usability studies, 4(3), 114-123.

Binder, T., De Michelis, G., Ehn, P., Jacucci, G., Linde, P., \& Wagner, I. (2011). Design Things. Cambridge, MA: The MIT Press.

Brooke, J. (1996). SUS: A “quick and dirty" usability scale. In P. W. Jordan, B. Thomas, B. A. Weerdmeester, \& I. L. McClelland (Eds.), Usability evaluation in industry (pp. 189-194). London: Taylor \& Francis.

Brooke, J. (2013). SUS: A Retrospective. Journal of Usability Studies, 8(2), 29-40.

Buchanan, R. (1995). Wicked problems in design thinking. In V. Margolin, \& R. Buchanan (Eds.), The idea of design : a Design issues reader (pp. 3-20). Cambridge: MIT Press. 
Goel, V. (1995). Sketches of Thought. Cambridge: The MIT Press.

Goel, V., \& Pirolli, P. (1992). The structure of design problem space. Cognitive Science, 16, 395-429.

Goldschmidt, G. (1991). The dialectics of sketching. Creativity Research Journal, 4(2), 123-143.

Harris, J. (2012). Digital practice in material hands: How craft and computing practices are advancing digital aesthetic and conceptual methods. Craft Research, 3(1), 91-112.

Hassenzahl, M., Law, E.-C., \& Hvannberg, E. T. (2006). User Experience - Towards a unified view. In M. Hassenzahl, E. L.-C. Law, \& E. T. Hvannberg (Eds.), User Experience - Towards a Unified View: Second International COST294-MAUSE Open Workshop (pp. 1-3). Oslo: COST.

Hsieh, H.-F., \& Shannon, S. (2005). Three approaches to qualitative content analysis. Qualitative health research, 1277-88.

ISO. (1998). ISO 9241-11: Ergonomic requirements for office work with visual display terminals (VDTs) -- Part 11: Guidance on usability. Geneva: International Organization for Standardization.

ISO. (2010). ISO 9241-210: Ergonomics of human-system interaction -- Part 210: Human-centred design for interactive systems. Geneva: International Organization for Standardization.

ISO/IEC. (2011). ISO/IEC 25010: Systems and software engineering -- Systems and software Quality Requirements and Evaluation (SQuaRE) -- System and software quality models. Geneva: International Organization for Standardization.

Jordan, P. (2000). Designing pleasurable products : An introduction to the new human factors. London: Taylor $\&$ Francis.

Jun-Chieh, W., Cheng-Chi, C., \& Hsin-Chia, C. (2012). Comparison of Designer's Design Thinking Modes in Digital and Traditional Sketches. Design and Technology Education: an International Journal, 17(3), $37-48$.

Lappola, K. (2014). The Pinterest project: Using social media in an undergraduate second year fashion design course at a United States University. Art, Design \& Communication in Higher Education, 13(2), 175187.

Lawson, B. (1997). How designers think? The design process demystified. (3rd ed.). Oxford: Architectural Press.

Masterton, D. H. (2007). Deconstructing the digital. New craft future voices: Proceedings of the dundee conference, july 04-06, 2007 (pp. 7-24). Dundee: Duncan of Jordanstone College of Art \& Design.

Mayring, P. (2000). Qualitative content analysis. Forum Qualitative Sozialforschung / Forum: Qualitative Social Research, 1(2).

McNamara, N., \& Kirakowski, J. (2006). Functionality, usability, and user experience: three areas of concern. interactions, 13(6), 26-28.

Nielsen, J. (1993). Usability Engineering. Boston: AP Professional.

Pahl, G., \& Beitz, W. (1996). Engineering Design: A Systematic Approach (2nd. ed.). (K. Wallace, Ed.) London: Springer.

Petre, M., Sharp, H., \& Johnson, J. (2006). Complexity through combination: an account of knitwear design. Design Studies, 27(2), 183-222. 
Philpott, R. (2010). Ways of knowing and making: searching for an optimal integration of hand and machine in the textile design process. Proceeding of the Textile Institute Centenary Conference: Textiles: a Global Vision. Manchester: The Textile Institute.

Ramduny-Ellis, D., Dix, A., Evans, M., Hare, J., \& Gill, S. (2010). Physicality in Design: An Exploration. The Design Journal, 13(1), 48-76.

Seffah, A., Donyaee, M., Kline, R. B., \& Padda, H. K. (2006). Usability measurement and metrics: A consolidated model. Software Quality Journal, 14(2), 159-178.

Sennett, R. (2009). The Craftsman. London: Penguin Books.

Stones, C., \& Cassidy, T. (2010). Seeing and discovering: how do student designers reinterpret sketches and digital marks during graphic design ideation? Design Studies, 31(5), 439-460.

Taylor, J., \& Townsend, K. (2014). Reprogramming the hand: Bridging the craft skills gap in 3D/digital fashion knitwear design. Craft Research, 5(2), 155-174.

Tullis, T. S., \& Stetson, J. N. (2004). A Comparison of Questionnaires for Assessing Website Usability. Usability Professional Association Conference, (pp. 1-12). Minneapolis, Minnesota.

Verbruggen, D. (2014). The Digital Craftsman and His Tools. In K. Bunnell, \& J. Marshall (Ed.), All Makers Now: Craft Values in 21st Century Production, International Conference Proceedings, Autonomatic Research Group, Falmouth University, 10/11 (pp. 173-177). Falmouth: Falmouth University.

Yin, R. K. (2003). Case Study Research, Design and Methods (3rd ed.). Thousand Oaks: Sage Publications.

Zoran, A., \& Buechley, L. (2013). Hybrid reAssemblage: An Exploration of Craft, Digital Fabrication and Artifact Uniqueness. Leonardo, 46(1), 4-10. 